\title{
Article
}

\section{Soil faunal and structural responses to the settlement of a semi- sedentary earthworm Lumbricus terrestris in an arable clay field}

Nuutinen, V., Butt, Kevin Richard, Hyvaluoma, J., Ketoja, E. and Mikola, J.

Available at http://clok.uclan.ac.uk/21302/

Nuutinen, V., Butt, Kevin Richard ORCID: 0000-0003-0886-7795, Hyvaluoma, J., Ketoja, E. and Mikola, J. (2017) Soil faunal and structural responses to the settlement of a semi- sedentary earthworm Lumbricus terrestris in an arable clay field. Soil Biology \& Biochemistry, 115 . pp. 285-296. ISSN 0038-0717

It is advisable to refer to the publisher's version if you intend to cite from the work. http://dx.doi.org/10.1016/j.soilbio.2017.09.001

For more information about UCLan's research in this area go to http://www.uclan.ac.uk/researchgroups/ and search for <name of research Group>.

For information about Research generally at UCLan please go to http://www.uclan.ac.uk/research/

All outputs in CLoK are protected by Intellectual Property Rights law, including Copyright law. Copyright, IPR and Moral Rights for the works on this site are retained by the individual authors and/or other copyright owners. Terms and conditions for use of this material are defined in the policies page. 
Soil faunal and structural responses to the settlement of a semi-sedentary earthworm Lumbricus terrestris in an arable clay field

Visa Nuutinen ${ }^{1}$, Kevin R. Butt ${ }^{2}$, Jari Hyväluoma ${ }^{1}$, Elise Ketoja ${ }^{1}$, Juha Mikola ${ }^{3}$

${ }^{1}$ Natural Resources Institute Finland (Luke), FI-31600, Jokioinen, Finland

${ }^{2}$ School of Forensic and Applied Sciences, University of Central Lancashire, Preston

PR1 2HE, United Kingdom

${ }^{3}$ Department of Environmental Sciences, University of Helsinki, Niemenkatu 73, FI-15140

Lahti, Finland

Corresponding author:

Visa Nuutinen (visa.nuutinen@luke.fi) 


\section{Abstract}

We studied the soil community and habitat consequences of introducing a deep-burrowing, sedentary life-style earthworm, Lumbricus terrestris (dew-worm) into arable zero-till clay. Seventeen years after introduction, which was originally aimed at improving the macroporosity and permeability of the heavy clay soil, we returned to the gradient of $L$. terrestris dispersal (well established, more recent and no settlement) and investigated the temporal development of the ecosystem engineering impacts on different faunal groups (earthworms, enchytraeids and nematodes) and soil porosity. The faunal responses were examined both at L. terrestris midden scale (individual living site) and field scale. We found that $L$. terrestris middens sustained elevated densities of all three faunal groups. In the case of earthworms, there was evidence for temporal development of the engineering impact as the difference between the midden and non-midden areas was more pronounced in the wellestablished areas than close to the leading edge of dispersal. The earthworm community composition was not altered at $L$. terrestris midden sites. The settlement of $L$. terrestris had no discernible effects on field-scale earthworm and nematode abundances, but enchytraeids were practically absent beyond the leading edge of the dispersal. This effect might, however, be partly explained by a gradient of increasing clay content. Soil macroporosity at $L$. terrestris midden sites did not increase with the age of L. terrestris settlement. Our results suggest that $L$. terrestris settlement in a clay soil can significantly increase the spatial patchiness of soil fauna, but may not, except in the case of enchytraeids, affect their fieldscale abundances or the macroporosity of the soil in the vicinity of L. terrestris living sites. 


\section{Introduction}

Understanding the effects of large and abundant invertebrate ecosystem engineers on smaller organisms has for long been a major assignment in soil ecology (Lavelle et al., 1997, 2016). The physical structures created by such organisms, with the various facilitative influences involved, are known to be of particular importance at small to medium scales of soil habitats (Ettema and Wardle, 2002; Wardle, 2006). Earthworms are allogenic ecosystem engineers (Jones et al., 1994), which through soil modification (Blouin et al., 2013) affect other soil organisms (e.g. Eisenhauer, 2010; Frouz et al., 2013) and plant growth (Scheu, 2000; van Groenigen et al., 2014). When ecosystem engineers reach novel environments, their impacts can be striking (Crooks, 2002), as demonstrated by earthworms. Earthworm invasions into forests, where the soil, organic matter properties and vegetation have developed in their absence, can result in startling changes in soil organic matter dynamics and plant community composition (e.g. Eisenhauer et al., 2012; Fugère et al., 2017; Hendrix, 2006). Alternatively, earthworm engineering can be actively used in environmental management (Baker et al., 2006). A special motivation for introducing earthworms on arable lands is to enhance and maintain the physical soil structure and its beneficial consequences for plant growth (Andriuzzi et al., 2015; Shipitalo and Le Bayon, 2004;).

Space and time matter in ecosystem engineering, with the spatial scale, nature and longevity of engineering all being important (Hastings et al., 2007). The ecological groups of earthworms differ considerably in these aspects, and Jouquet et al. (2006) therefore suggested a distinction between "accidental" and "extended phenotype" engineers. The former include species, which move around in the soil when searching for resources and optimal environmental conditions and which do not create distinct structures of great longevity, while the latter involve species that produce specific, persistent structures to secure favorable living conditions. In this typology, the dew-worm Lumbricus terrestris L. represents the "extended 
phenotype" engineering: the mature individuals occupy a spatially distinct living-site with a deep, permanent home-burrow. The burrow opens at the soil surface, where the nocturnally collected plant litter and casts (solid excrements) form a distinct mound, a midden. This lifestyle is called anecic in the ecological classification of earthworms (Bouché, 1977). The middens are biological hotspots, which differ from the surrounding soil in many biological and physico-chemical attributes, such as microbial activity and $\mathrm{C}$ and $\mathrm{N}$ content (Subler and Kirsch, 1998), micro- and mesofaunal communities (Maraun et al., 1999), and macrofaunal abundance and greenhouse gas emissions (Nieminen et al., 2015).

In undisturbed habitats, the dew-worm living sites are remarkably permanent (Grigoropoulou and Butt, 2010). The age of middens can exceed the known maximum life span of individuals (Nuutinen, 2011) and the burrows are passed on in a population through ecological inheritance (sensu Odling-Smee et al., 2013). In forest soils, this can lead to a development of distinct soil micro-relief with regularly spaced middens (Hazelhoff et al., 1981). It is likely that the type of habitat modification, which characterizes L. terrestris activity, develops over time and that the tempo and mode of its impacts vary for different target organisms. So far, however, this aspect of earthworm soil modification has not been addressed. In our study, we investigated the patterns of soil structure and abundance of selected soil animal groups in an arable field along the dispersal gradient of an introduced $L$. terrestris population. The study was conducted at a site of extremely high clay content. Clay is a demanding environment for soil dwelling animals and the potentially facilitative processes of habitat modification are supposed to be of particular importance under such hard conditions (Bruno et al., 2003). The original aim of L. terrestris inoculation at the site was to improve soil physical structure for crop cultivation (Nuutinen et al., 2006) and the enhanced earthworm (Butt \& Lowe, 2007; Nieminen et al., 2015) and enchytraeid (Schrader and Seibel, 2001) activity in the midden soil should help the process by increasing soil porosity. 
We hypothesized that (1) top soil porosity at the immediate vicinity of L. terrestris middens increases with increasing timespan of $L$. terrestris occupation. We also predicted that, probably through the accumulation of coarse organic matter, (2) the midden areas favour

litter-associated epigeic earthworms and L. terrestris juveniles (Butt and Lowe, 2007; Uvarov, 2009), as well as enchytraeids (detritus feeding mesofauna) and nematodes (microfauna of different trophic groups), which both interact with earthworms (Karaban and Uvarov, 2014; Schlagmerský et al., 2014; Tiunov et al., 2001) and have important roles in arable detritus-based food webs (Didden, 1990; Yeates, 2007). Considering the development of the engineering impact over time, we hypothesized that (3) the L. terrestris living sites are more distinct from their surroundings in the earlier settled areas than in the leading edge of the dispersal gradient. Finally, by examining the field-scale impacts of L. terrestris engineering, we predicted that (4) the overall abundances (summing up the midden and nonmidden areas) of the faunal groups are higher in the occupied than unoccupied areas.

\section{Materials and Methods}

\subsection{Study site}

The study was conducted at the Kotkanoja experimental leaching field, established in 1975 on an arable field in Jokioinen, southwest Finland (6049’N, 2330'E) (Jaakkola, 1984; Turtola et al., 2007). The average annual precipitation in Jokioinen is $627 \mathrm{~mm}$ and the average annual temperature $4.6^{\circ} \mathrm{C}$, while the coldest and warmest months are February ($\left.6.3^{\circ} \mathrm{C}\right)$ and July $\left(16^{\circ} \mathrm{C}\right)$ (Pirinen et al., 2012). The snow cover lasts from November or December until April, and during this period, the soil is frozen to an average depth of $0.4 \mathrm{~m}$ (mean of years 1980-2001 in Turtola et al., 2007). The soil in the field is classified as Stagnosol (IUSS Working Group WRB, 2015) and has a mean clay content of $61 \%$ in the topsoil (0-0.25 $\mathrm{m})$ and $90 \%$ in the subsoil (0.4-0.8 $\mathrm{m})$. 
To lower the high water table level, the field was subdrained with tile drainage pipes, laid at a depth of $1 \mathrm{~m}$ and $16.5 \mathrm{~m}$ apart in 1962 (subdrains are installed at the bottom of narrow trenches, which are then backfilled). In 1975, when the leaching field was established, the tiles were connected to plastic cross pipes to form drainage plots, arranged in four strips. New plastic drain pipes were further installed in 1991 at the same depth as the old tile pipes, $0.3 \mathrm{~m}$ apart from the tiles, and connected to the cross pipes (Turtola 1999). For the present study, it is noteworthy that the soil environment close to subdrains is known to be favourable for deep burrowing earthworms, possibly due to the low water table near the drains (Nuutinen et al. 2001).

The experimental design of the leaching field consists of four adjacent $33 \mathrm{~m} \times 140 \mathrm{~m}(0.5 \mathrm{ha})$ treatment strips, separated by $1 \mathrm{~m}$ wide grass strips and surrounded by permanent grassland (Fig. 1). The field has an average slope of $2 \%(1-4 \%)$, and within the two field strips used in this study (Fig. 1, Strips 1 and 2), the topsoil $(0-20 \mathrm{~cm})$ clay content gradually increases downslope, from loamy to heavy clay. The clay content is lowest (43\%) close to tiles 1 and 2 in Strip 1 and highest (79\%) close to tiles 5 and 6 in Strip 2, obviously due to a relatively steep slope at this part of the field (Fig. S1; Turtola and Jaakkola, 1987). In the two strips, the current median C content at 0-0.1 m depth is 3.5\% of soil dry mass (range 2.8-4.2\%) and median pH 6.3 (6.1-6.4). There are no obvious, consistent differences between the strips or trends along the slope, except for the downslope increase in clay content. In both strips, the soil bulk density at $0-0.1 \mathrm{~m}$ depth varies between 1.07 and $1.20 \mathrm{~g} \mathrm{~cm}^{-3}$.

In October 1996, L. terrestris (dew-worms), which had earlier been absent from the field and its surroundings, were inoculated in the field using the Earthworm Inoculation Unit (EIU) technique (Butt et al., 1997). The worms were inoculated at the up-slope end of the field, both inside the field (to a maximum distance of $8 \mathrm{~m}$ from the field margin) and in the field and strip margins. The inoculation procedure and spatial design are described in Nuutinen et al. 
(2006). Subsequent monitoring showed that after the initial period of survival and population growth in the field and strip margins only, the population started to settle inside the field with an average spread of $4.6 \mathrm{~m} \mathrm{yr}^{-1}$ down the field (Nuutinen et al., 2011).

From the 1996 inoculation till the present study, except for a set-aside period under grass during 2002-2008, the field was used for spring cultivation of barley (Hordeum vulgare), wheat (Triticum aestivum) and oats (Avena sativa) using alternating rotation and always one crop covering the whole field. Since 2008, two of the four strips have been under direct drilling, while the other two have been mouldboard ploughed in the autumns (Nuutinen et al., 2011). In the present study, we utilized the two directly tilled strips, denoted as Strips 1 and 2 (Fig. 1), in which the dew-worm population is known to be spreading (Nuutinen et al., 2011). The strips have been under conventional management with mineral fertilization and regular herbicide treatments: for instance, in the 2012 growing season with barley cultivation, the NP-K fertilizer was applied at a rate of 90-24-24 $\mathrm{kg} \mathrm{ha}^{-1}$ during spring sowing, and weeds were sprayed in the summer and autumn using standard application rates of MCPA (Ariane S) and glyphosate (Glyfokem), respectively. Our field data was collected in May 2013 prior to sowing. We started our study by mapping the dew-worm distribution and then sampled the soil for earthworms, physical soil structure and selected soil animals.

\subsection{L. terrestris distribution gradient}

To find the gradient of L. terrestris dispersal from the settled areas to the leading edge, the distribution of dew-worms in Strip 1 and 2 was mapped by counting the surface middens, a reliable indicator of dew-worm presence at the prevailed conditions (see e.g. Singh et al., 2015). As the dew-worms at the site abound close to the subdrains (Nuutinen et al., 2011), midden counts were carried out above the subdrain lines (Fig. 1). Each count covered $0.5 \mathrm{~m}^{2}$ and three separate sites were chosen above each line: i.e. at the strip center and at a $6 \mathrm{~m}$ distance from both strip margins (Fig. 1). Midden counts started at the upper end of the field 
and continued down the slope until no middens were observed above two successive subdrain lines, which in both strips occurred at the sixth line (Fig. 1).

\subsection{Soil animal sampling}

Based on the midden distribution pattern, three dispersal zones were selected from both strips. Zone 1 is aimed to represent a well-established area with potentially old middens. This zone was positioned close to subdrain line 1 in both strips (Fig. 1). Zone 2 is aimed to represent an area close to the leading edge of L. terrestris dispersal with potentially younger middens. Because of more rapid earthworm dispersal in Strip 1 than Strip 2, this area was placed close to subdrain line 3 in the former and close to line 2 in the latter. In Zone 1, the sampling areas were chosen close to the strip margins as these were thought to have particularly old middens. In Zone 2, by contrast, the soil was sampled close to the strip center to select as young middens as possible. Zone 3 is an area with no dew-worm middens and is beyond the leading edge of the population spread. In Strip 1 this zone was placed close to subdrain line 5 and in Strip 2 close to line 3 as in Strip 2 the population density of $L$. terrestris, possibly due to a stronger clay gradient, waned earlier.

To sample for earthworms, ten pairs of well-developed middens and adjacent control spots with no midden were chosen in Zones 1 and 2 of both Strips 1 and 2. A cylindrical soil sample (diameter $15 \mathrm{~cm}$, depth $10 \mathrm{~cm}$ ) was taken at the place of each midden and control spot using a trowel. The midden soil and surface straw were sampled separately. Mustard suspension was then poured to sampling pits to obtain resident dew-worms (Gunn, 1992), which typically are missed using top-soil sampling. The median distance between the outer rims of the midden and control samples was $13 \mathrm{~cm}$. In Zones 3, ten randomly placed soil samples were taken without subsequent mustard application. Based on the previous work at the site, the absence of middens is a reliable sign for the absence of large L. terrestris individuals and this was confirmed while hand-sorting the Zone 3 soil samples, which had no 
L. terrestris burrows or juvenile individuals. Soil temperature was $10-13^{\circ} \mathrm{C}$ at a depth of 10 cm during sampling. Earthworms obtained using the mustard suspension were identified, their wet mass was recorded and the animals were released close to the site of collection. The soil samples were preserved at $6^{\circ} \mathrm{C}$ for $2-3 \mathrm{~d}$ before earthworms were hand sorted from the soil and stored in 85\% alcohol for later identification (Sims and Gerard, 1999) and mass determination.

Soil moisture was determined by drying sub-samples of hand-sorted soil overnight at $105^{\circ} \mathrm{C}$ (five pairs of samples for Zones 1 and 2, five samples for Zones 3). The soil under the middens was moister than the non-midden soil in Zone 1, although much less so in Strip 2, but did not differ from the non-midden soil in Zone 2 (Fig. 2). In both strips, soil moisture increased from Zone 1 to Zone 3 (Fig. 2), possibly due to the downslope gradient and the associated higher clay content.

For estimating the effects of dew-worms on the abundance of soil micro- and mesofauna, five midden and five non-midden soil cores were collected from each Strip $\times$ Zone combination for nematodes (depth $5 \mathrm{~cm}$, diameter $3 \mathrm{~cm}$ ) and enchytraeids (depth $5 \mathrm{~cm}$, diameter $5.3 \mathrm{~cm}$ ). Within a treatment pair, the distance between the midden and non-midden core center was 15 cm. Nematodes and enchytraeids were extracted using wet funnel devices (O’Connor, 1962; Sohlenius, 1979). For the nematode extraction, the soil samples were gently broken and homogenized and the animals were extracted from sub-samples of soil for $18 \mathrm{~h}$ in a shallow mesh tray at room temperature without light. The enchytraeid soil cores were placed intact and upside down in mesh cylinders (lined with $0.4 \mathrm{~mm}$ mesh fabric to restrain the soil running to the collection tube) and the animals were extracted for $4 \mathrm{~h}$ by gradually increasing light and heat stress with $40 \mathrm{~W}$ light bulbs placed above the samples. 


\subsection{Analysis of soil porosity}

To examine soil porosity, intact soil cores were collected from Strip 1 (five pairs from both Zone 1 and Zone 2) and imaged using x-ray computed tomography. Soil cores were sampled stepwise by first manually excavating a soil core slightly larger than the sample cylinder and then pressing the cylinder downwards. At each step, the trench around the cylinder was $1 \mathrm{~cm}$ deeper. This process was repeated until the intended depth was reached. The cylinder was then carefully removed and the lower end of the sample trimmed. Each sample pair consisted of a midden and non-midden core, with a distance of sample outer rims of 20-30 cm. Soil cores were sampled using acrylic cylinders of three different inner diameters $(94,127$, and $144 \mathrm{~mm}$ ), height of $15 \mathrm{~cm}$ and wall thickness of $3 \mathrm{~mm}$. Three different diameters were used to ensure that reliable information would be obtained as there was no certainty whether the largest samples could be imaged with sufficient quality. At the end, all core sizes permitted a good-quality image by tomography. After collecting porosity samples, earthworms were extracted from the attained pits using another dosage of mustard suspension, the worms were identified, weighed and returned close to the site of collection. On average, one L. terrestris individual (number varying from zero to two individuals, fresh mass from 0.9 to $4.1 \mathrm{~g}$ ) was obtained from both the midden and control sampling pits, indicating that slanted L. terrestris burrows entered the control area.

To avoid disturbance to the macropore structure due to earthworm activity during storage, the collected soil cores were kept frozen for $4 \mathrm{~d}$ and allowed to thaw at room temperature for 2-3 d prior to analyses. Soil cores were scanned using a medical cone beam computed tomography scanner (Planmeca ProMax 3D Max) at the University Hospital in Tampere, Finland. The tomography scans used a view of $100 \times 130 \mathrm{~mm}^{2}$ and a voxel size of $200 \mu \mathrm{m}^{3}$. From each image, a cylindrical region was selected to image process in a way that maximized the imaged sample volume and excluded possible sampling artefacts near the edges. As beam 
hardening artefacts were observed in the images, a radial intensity correction algorithm was utilized (cf. Iassonov and Tuller, 2010), i.e. the samples were divided into 15 nested coaxial cylindrical layers and the average intensity and a correction factor was calculated for each layer. Radial intensity profile was straightened by using a correction factor for each voxel. These were interpolated from the layer factors to achieve a smooth correction. To reduce imaging noise, a 3D median filter (radius 2) was applied. Images were segmented into two classes (pores and solids) using a method based on the minimization of intra-class variance (Otsu, 1979). Otsu's method assumes that grey-scale values in the image correspond to two different classes only, but this is not true for soils where the solid phase is composed of organic matter and various minerals and therefore has a wide range of grey-scale values. To cope with such heterogeneous materials, Hapca et al. (2013) introduced an extension to Otsu's method, where part of the voxels is first pre-classified to belong to the solid phase and Otsu's segmentation is then performed for the unclassified voxels. As Hapca et al. (2013) found that the original Otsu's threshold value worked as a pre-classification threshold for most soils, we also used this approach. To account for the vertical intensity variations, segmentation was performed layer-wise (25 layers) and the final threshold values were interpolated from layer thresholds. After segmentation, a 3D majority filter with radius 2 was applied to images. The location of the soil surface was identified using an interface detection algorithm (Turpeinen et al., 2015) and the void space above the sample was excluded from the image analysis.

Segmented images were then used to estimate the porosity (proportion of pore volume of total sample volume) and pore-size distribution. The pore-size distribution was estimated using mathematical morphology (Horgan, 1998), in which the image is probed with a structuring element (spherical in our case). The two fundamental morphological operations are erosion and dilation: the former erodes the boundaries of the object (here the pore space) 
depending on the size of the structuring element, while dilation is a complementary (but not inverse) operation, which enlarges the object depending on the size of the structuring element. Morphological opening is achieved when erosion is followed by dilation and can be used to eliminate small pores and make pore boundaries smoother. Pore-size distribution is obtained by applying successively morphological openings with a gradually increasing structuring element (Hilpert et al., 2003). As the main L. terrestris burrow is connected to the surrounding pore space, the burrow has to be omitted from the image analyses of midden samples to estimate the pore space. For this purpose, we developed a method that utilizes the morphological opening process and a flood fill algorithm (also known as bucket fill in raster graphic programs). The algorithm starts from a seed voxel and floods all connected voxels with a replacement "colour". In our case, we selected the seed voxel from the earthworm burrow and filled all connected pore space. This space was then tagged as "burrow" and morphologically opened by a spherical structuring element with a radius of 5 voxels $(1 \mathrm{~mm})$. The opening cut off those small pores that were connected to the burrow and allowed the remaining burrow voxels to be excluded from the analysis.

\subsection{Statistical analyses}

The values of the response variables were non-normally distributed and therefore analysed using generalized linear mixed models (Gbur et al., 2012), whose distributional assumptions and link functions are listed in Table 1. The chosen link functions are commonly used for the distributions and also adequately fitted our data. The original sample area of each faunal group was used in the statistical analyses and is also used in the units of the figures, except

that the total number of middens was multiplied by two to obtain a conventional unit of $\mathrm{m}^{-2}$. Transforming the other faunal data to the unit of $\mathrm{m}^{-2}$ would have eased the comparison of population densities with earlier studies, but would have produced ambiguous densities for 
midden samples, whose area consists of the midden and surrounding soil and cannot simply be multiplied.

The relationship between the number of middens and the distance from the original $L$. terrestris inoculation was modelled separately for the two Strips using a logarithmic scale and low-degree polynomials (Table 1). A second-degree polynomial with site-specific intercepts adequately fitted the data of the three sites (centerline and two margins) in Strip 1, whilst a first-degree polynomial with site-specific intercepts was an appropriate model for Strip 2. The random site effect was tested using a likelihood ratio chi-square test (SAS Institute 2015).

For analysing the data of soil fauna at the midden scale (five response variables, Table 1), the main effects of Strip, Zone, Midden (midden vs. non-midden soil) and their two-way and three-way interactions were included in the models as fixed effects and the effect of midden non-midden pair as a random effect. The pair effects were assumed to be normally and independently distributed with zero mean and constant variance. To compare the three Zones in terms of overall faunal abundance (three response variables, Table 1), weighted averages were calculated using the proportions of midden and non-midden soil (producing field-scale, in comparison to midden-scale, estimates of faunal abundance) and only the fixed effects of Strip, Zone and their interaction were included in model equations. The models for porosity (with the main L. terrestris burrow included or excluded) included the effects of Zone, Midden and their interaction as fixed effects and the pair as a random effect.

The models were fitted using integral approximation (Gauss-Hermite quadrature) and a biasadjusted sandwich estimator (Morel et al., 2003). Statistical significances of the fixed effects were determined through Wald F-tests, where degrees of freedom were calculated using the containment method (Gbur et al., 2012). Means were estimated using the models on the link 
scale and converted back to the data scale by applying an inverse link function. Standard errors of means (SEMs) were obtained by the Delta method (Gbur et al., 2012). To check model assumptions, Pearson residuals were plotted against the linear predictor. In the count data, overdispersion was diagnosed using the Pearson goodness of fit statistic, while the adequacy of link functions was tested by plotting each response variable, transformed to the link scale, against the linear predictor (Gbur et al., 2012). The modelling was performed using the GLIMMIX procedure of the SAS/STAT software (version 9.3; SAS Institute, 2015).

\section{Results}

\subsection{L. terrestris distribution gradient}

The occurrence of $L$. terrestris middens gradually diminished away from the original inoculation area, where densities close to 30 middens $\mathrm{m}^{-2}$ were found, with no middens found beyond subdrain line 4 (at 54 m distance) in either strip (Fig. 3). The density of middens was somewhat higher in Strip 1 than Strip 2 along the entire dispersal gradient. In both strips, the density of middens was lower at the centreline than at the margins, although this pattern was more pronounced in Strip $2\left(\chi^{2}=17.45, \mathrm{df}=1, \mathrm{P}<0.0001\right)$ than Strip $1\left(\chi^{2}=2.08, \mathrm{df}=1, \mathrm{P}=0.07\right)$.

\subsection{Soil fauna}

Earthworm individuals were dominated by endogeic species, i.e. Aporrectodea caliginosa Sav. (15\% of individuals), A. rosea Sav. (1\%) and Aporrectodea sp. (52\%). Anecic species consisted of the introduced L. terrestris (10\%), and the epigeic species of L. castaneus Sav. (3\%), Dendrobaena octaedra Sav. (3\%) and L. rubellus Hoffm. (2\%). The remaining individuals were classified as Lumbricus sp. (14\%). The mustard extraction in Zones 1 and 2 yielded a L. terrestris individual in seven midden locations. These individuals were large 
juvenile or mature individuals (1.9-3.8 g each) and are excluded from the subsequent analyses of earthworm community composition and total abundance.

Earthworm community composition did not differ between midden and non-midden soils: in the midden soil, the combined proportion of anecic and epigeic species of all earthworm individuals was on average $31 \%(\mathrm{SEM}=5 \%)$ and in non-midden soil 34\% (SEM=6\%) (Table 2). Total number of earthworms was higher in the midden than non-midden soil in Zone 1 ( $\mathrm{P}<0.0001)$, but not in Zone $2(\mathrm{P}=0.45)$ (Table 2, Fig. 4), whilst total mass in both zones was higher in the midden soil (mean $0.51 \mathrm{~g}, \mathrm{SEM}=0.11 \mathrm{~g})$ than in the non-midden soil $(0.32 \mathrm{~g}$, SEM=0.06 g; Table 2). Strips and zones did not differ in earthworm numbers, but earthworm mass was on average higher in Strip $2(0.58 \mathrm{~g}, \mathrm{SEM}=0.11 \mathrm{~g})$ than Strip 1 ( $0.28 \mathrm{~g}, \mathrm{SEM}=0.06$ g) (Table 2). The overall, combined abundance of endogeic and epigeic earthworms (including midden and non-midden areas in their relative proportions) tended to increase from Zone 1 to Zone 3, but the Zone effect was not statistically significant (Table 3, Fig. 6). The nematode abundance was $53 \%$ and the enchytraeid abundance $225 \%$ higher in the midden than non-midden soil (Fig. 5, Table 4). The difference in nematode abundance was, however, statistically non-significant due to one deviant midden - non-midden pair (Table 4). In this pair, the number of nematodes was 46 and 445 ind. $\mathrm{cm}^{-2}$ in the midden and nonmidden soil, respectively, whereas in 15 of the 20 data pairs the numbers were higher in midden soil. After excluding the deviant pair, the nematode abundance was $88 \%$ higher in the midden than non-midden soil and the difference was statistically significant (Table 4). The overall abundance of nematodes did not differ among the three zones (Fig. 6, Table 3). In contrast, while the enchytraeids were present in equally low abundances in Zone 1 (mean frequency 0.63 per sample; SEM=0.36 ind.) and Zone 2 (0.60; SEM=0.38, $\mathrm{P}=0.95$ for the difference), they were practically absent from Zone 3 (no individuals in nine samples out of ten; seven individuals in the one occupied sample). 


\subsection{Soil porosity}

Porosity did not differ between Zones 1 and 2 regardless of whether the main burrow was included $(\mathrm{P}=0.57)$ or excluded $(\mathrm{P}=0.72)$ from the analysis. Porosity was also similar in the midden and non-midden samples $(\mathrm{P}=0.20)$ and especially so when the main L. terrestris burrow in the midden samples was excluded from the analysis $(\mathrm{P}=0.95)$ (Fig. 7, top). An example of the pore-size analysis shows the main L. terrestris burrow and the narrower burrows in its vicinity in a typical situation, where the main burrow descended at a slant and was not captured in the sample for its whole length (Fig. 7, bottom).

In Zone 2, the non-midden samples had a higher volume of large pores in the pore-size distribution than in Zone 1 (Fig. 8), which was due to the earthworm burrows being found from deeper layers in three of the five control samples in this zone. In the midden samples, the pore-size distribution exhibited a clear bimodal character due to the large L. terrestris main burrow, but when the burrow was excluded from the analysis, the pore-size distribution of midden and control samples appeared similar (Fig. 8).

\section{Discussion}

4.1. Impacts on fauna at the midden scale

As we predicted, the L. terrestris midden sites were microenvironments of elevated faunal density for nematodes, enchytraeids and other earthworms. In the case of earthworms, we also found evidence of population densities increasing with longer L. terrestris settlement. In contrast to our predictions, however, the earthworm community in L. terrestris middens had the same composition of ecological groups and the soil the same macroporosity as the control soil.

In earthworm invasion ecology, the middens of anecic species represent a special case of intense engineering of soil small-scale heterogeneity (Migge-Kleian et al., 2006). Middens of 
L. terrestris have frequently been described as biological hot-spots, where the accumulated coarse litter and high C, N and soil moisture levels (e.g. Maraun et al., 1999; Nieminen et al., 2015; Subler and Kirsch, 1998) support elevated microbial (Aira et al., 2009) and animal (Butt and Lowe, 2007; Eisenhauer, 2010; Nieminen et al., 2015; Schrader and Seibel, 2001; Stroud et al., 2016) abundances. Only exceptionally has this pattern remained unnoticed (Straube et al., 2009) and our results clearly agree with the hot-spot conception.

The ecological interactions of earthworms with nematodes and enchytraeids are multifaceted, involving competitive, predatory and facilitative processes, and their outcome appears context-dependent (e.g. Beylich and Graefe, 2012; Brown, 1995; Karaban and Uvarov, 2014; Räty and Huhta, 2003; Schlaghamerský et al., 2014). However, in agreement with our findings, earlier investigations have found elevated densities of both groups in L. terrestris middens; nematodes in forest soils (Maraun et al., 1999) and enchytraeids in forest and arable soils (Schrader and Seibel, 2001; Schlaghamerský et al., 2014). In addition to middens, nematodes are also known to thrive in the burrow walls of anecic earthworms (Andriuzzi et al., 2016; Görres et al., 1997; Tiunov et al., 2001). The response to earthworm activity apparently varies among trophic groups and species, and according to earlier investigations, the large enchytraeid species with good dispersal capacity (Schlaghamerský et al., 2014) and the bacterial-feeding nematodes (Maraun et al., 1999) seem to be particularly abundant in middens. Disentangling the mechanisms by which earthworm activity affects other fauna is a complex task as the mechanisms involve both trophic and non-trophic, species-specific influences as shown for enchytraeids by Karaban and Uvarov (2014). However, considering that nematodes are aquatic organisms whose activity concentrates in water films surrounding soil particles (Neher, 2010) and that enchytraeids are ill-equipped to tolerate dry soil conditions (Didden, 1993), it is possible that the slightly elevated water concentration in the midden soil in Zone 1 benefited both groups. Moreover, since microbes constitute an 
important resource for both groups, the enhanced microbial growth in middens (Aira et al. 2009), although not verified in our study, could contribute to the observed higher densities.

Individuals of L. terrestris lay cocoons in the upper part of their burrows, where the juveniles hatch and spend their early life in the midden nursery environment (Butt and Lowe, 2007; Grigoropoulou and Butt, 2009). The reproduction of the resident worm is therefore a key source of the earthworm population found in the middens. Based on the present and earlier studies (Nieminen et al., 2015), the population densities of endogeic, subsurface feeding species are also relatively high in the midden soil. This may partly relate to the favourable moisture conditions, but most likely also to the incorporation of plant surface residues and their modification into a more palatable form through digestion by the resident worm (Butt and Lowe, 2007; Uvarov, 2009). We expected that the epigeic, litter-feeding species would be positively associated with the midden environment, but found no evidence for this. The generally low abundances of epigeics in the field may be one explanation, but it is also possible that competition by the resident $L$. terrestris negatively affects the epigeics, such as D. octaedra, as has been shown in experimental conditions (Cameron and Bayne, 2011) and recent field surveys (Fugère et al., 2017).

The apparent inconsistency in the response of the three faunal groups to the L. terrestris dispersal gradient - i.e. a larger midden vs. non-midden difference at earlier (Zone 1) than later (Zone 2) settled areas in earthworm abundance, but not in nematode or enchytraeid abundance - calls for an explanation. The density of earthworms per unit area was relatively low in our study, and for earthworms, the population growth at middens may have mostly resulted from immigration. In such case, the increase in earthworm population densities in the middens may be relatively slow and the age of the midden matters. The maximal population growth rate for nematodes and enchytraeids is, due to their short generation time and high fecundity (e.g. Eijsackers, 2011; Nordström, 1976; Procter, 1986; Rodriquez et al., 2002), 
considerably higher than for earthworms and it is likely that L. terrestris activity can trigger a rapid growth in nematode and enchytraeid populations. In such case, the abundance of animals would not depend on the age of $L$. terrestris settlement. The rapid response of nematodes to earthworm presence and absence was recently illustrated by Andriuzzi et al. (2016), who found a decline of nematode numbers in the anecic earthworm (L. centralis) drilosphere within $50 \mathrm{~d}$ after removing the resident worm.

The similarity of responses of smaller animals to L. terrestris activity in different parts of the dispersal gradient may also be due to smaller than supposed differences in midden structure and age between these areas. Firstly, despite the relatively low mechanical disturbance under direct drilling, the mechanical interference of topsoil during sowing, spraying and harvest operations may equally restrain the development of middens across all zones. Second, the age difference of the middens along the dispersal gradient may not be as large as we supposed. Particularly in Strip 2, the midden density was low even in close vicinity of the initial inoculation area, which suggests that the L. terrestris population in Strip 2 was not selfsustaining, but still dependent on immigration from other areas (see Nuutinen et al., 2006, 2011). If this is the case, the midden age differences between our study zones were effectively diluted.

\subsection{Impacts on fauna at the field scale}

Local ecosystem engineering effects may translate into large-scale community changes (Jones et al. 1997) and cases of increased species richness and modification of community composition have been described (e.g. Donadi et al., 2015 and refs. therein). In our study, the introduction of L. terrestris was not associated with clear changes of the field-scale mean abundance of earthworms and nematodes, although there was a statistically non-significant tendency of increasing earthworm abundance along the dispersal gradient. In Zone 1, the $L$. terrestris activity seemed to concentrate earthworms in the middens and lower the inter- 
midden densities. These findings resemble the results in Eisenhauer's (2010) meta-analysis, where elevated densities of microarthropods in L. terrestris middens did not lead to increased densities at the habitat scale. We did, however, observe that enchytraeids were practically absent beyond the range of $L$. terrestris. This pattern could relate to the higher clay content downslope in the field, although we are not familiar with studies that had demonstrated negative effects of clay content on enchytraeid abundances. Instead, our finding agrees with earlier discoveries in two forest sites, where the leading edge of $L$. terrestris invasion had lower enchytraeid population densities than the already invaded area (Schlaghamerský et al., 2014). Although enchytraeids in arable fields benefit from no-till management, they seem to gain from moderate mechanical loosening of the soil (van Capelle et al., 2012). In the compact clay soils, L. terrestris is likely to "loosen" the environment through bioturbation besides enriching the soil with pre-digested organic matter and associated micro-organisms. These effects probably explain the pattern of enchytraeid abundances we observed and represent a special case of smaller organisms benefiting from the heterogeneity produced by a habitat-forming species (Bruno et al., 2003).

\subsection{Impacts on soil porosity}

The general level of soil porosity in our study, ca. $3 \%$, is close to the $2.5 \%$ volume density of earthworm burrow systems reported earlier from tomographical analyses of pasture soil (Bastardie et al. 2005). In the visual field counting of earthworm burrows, the lower limit of burrow diameter is conventionally set to $2 \mathrm{~mm}$ (Ligthart et al., 1993; Pérès et al., 2010; Pitkänen and Nuutinen, 1997). However, the smallest earthworm burrows can be narrower, close to $1 \mathrm{~mm}$ (Lee 1985; Edwards and Bohlen, 1996), and the pore size distribution peaks below $2 \mathrm{~mm}$ that we observed may have mostly resulted from earthworm burrowing. In contrast to what we expected, however, the imaging did not show clear differences in porosity between the midden and control samples or between the different zones. While $L$. 
terrestris individuals had a clear effect on the pore-size distribution by contributing to the widest burrow diameter classes, their presence was not reflected as higher porosity in the soil surrounding the main burrow. There are at least three factors, which may explain this. First, the higher soil moisture that we observed in the midden-associated soil samples may lower the burrowing activity of $A$. caliginosa and L. terrestris (Perreault and Whalen, 2006). Second, because of burrow backfilling by earthworms, porosity is not necessarily a simple increasing function of earthworm population density (Capowiez et al., 2014; Whalen et al., 2015). Third, the prominent compaction of the drilosphere by L. terrestris can reduce the porosity close to the burrow (Schrader et al., 2007).

It is obvious that the resolution of our tomography scanner could not detect all possible changes in the pore structure, and especially not at the lower end of pore diameter influenced by enchytraeids. Previous work has shown that enchytraeids can substantially contribute to soil porosity. For instance, Didden (1990) concluded that enchytraeids can raise the volume of soil pores that correspond to their body diameter and also increase pore continuity. Similarly, van Vliet et al. (1993) found increasing porosity caused by enchytraeid activity, which in their experiments, however, waned over time as the pores became filled by enchytraeid excrements. In recent experiments, enchytraeids were found to increase volumetric air content by creating a continuous network of pores of $0.5-0.7 \mathrm{~mm}$ in diameter (Porre et al. 2016). It is therefore likely that the elevated enchytraeid densities that we found in the midden soil were associated with increased soil porosity, although we could not detect this trend with the resolution of our imaging.

The accuracy of soil structure imaging was hampered by the difficulty of obtaining satisfactory soil samples. In a number of cases, the imaging revealed signs of L. terrestris burrows in the control cores, entering them horizontally, although inspection of the soil surface revealed no signs of middens. The fact that $L$. terrestris individuals were found at the 
bottom of some non-midden samples also illustrates the difficulty of obtaining samples clearly affected or not affected by L. terrestris. Overall, it appears that soil sampling in the present context is a non-trivial task and in future studies it might be worthwhile to collect a significantly larger number of samples to be able to reject the unsatisfactory ones. Moreover, while the modern imaging devices can capture even sub-micron details, they require a very small sample size, which complicates the analysis of pore structure at high spatial resolution.

\section{Conclusions}

Our results show how settlement of an earthworm species with a sedentary life style can lead to development of a patchy small-scale landscape with highly variable faunal activity. The effect appears to be similar across different size classes and functional groups of the animal community, but apparently does not take place at the same tempo. The pace of population growth at midden sites may depend on the relative importance of reproduction and immigration in the population dynamics of the given taxa. The impact of L. terrestris dispersal on the overall density of other fauna at the field scale also appeared to differ depending on the faunal group, with enchytraeids increasing, earthworms possibly decreasing and nematodes having no response. In our study, these effects were, however, relatively weak, some of them statistically non-significant and their interpretation was partly confounded by the variation of soil texture along the $L$. terrestris dispersal gradient. What was clear, however, is that the engineering effect of $L$. terrestris activity induced a spatial reorganization of animal abundances. In less frequently tilled and no-till arable soils, $L$. terrestris is often a key contributor to many aspects of soil quality (Briones and Schmidt, 2017) and looking more closely at the consequences of such reorganization would be intriguing from the viewpoint of field soil management. 


\section{Acknowledgements}

We thank Riitta Lemola and Eila Turtola for providing background information, Vesa Niemi for the help in the field and laboratory, Tapio Salo for sharing information, Harri Lilja for his help with the digital elevation model illustration, Jaakko Heikkinen for aerial photography and Jorma Järnstedt for the access to the x-ray tomography facilities at the Tampere University Hospital. The critical comments by two anonymous reviewers are gratefully acknowledged. The study is a part of the SAMARA-project supported by a grant to JH from the Maa- ja vesitekniikan tuki ry.

\section{References}

Aira, M., McNamara, N.P., Piearce, T.G., Dominguez, J., 2009. Microbial communities of Lumbricus terrestris L. middens: structure, activity, and changes through time in relation to earthworm presence. Journal of Soil and Sediments, 9, 54-61.

Andriuzzi, W.S., Ngo, P.-T., Geisen, S., Keith, A.M., Dumack, K., Bolger, T., Bonkowski, M., Brussaard, L., Faber, J.H., Chabbi, A., Rumpel, C., Schmidt, O., 2016. Organic matter composition and the protist and nematode communities around anecic earthworm burrows. Biology and Fertility of Soil, 52, 91-100.

Andriuzzi, W.S., Pulleman, M.M., Schmidt, O., Faber, J.H., Brussaard, K., 2015. Anecic earthworms (Lumbricus terrestris) alleviate negative effects of extreme rainfall events on soil and plants in field mesocosms. Plant and Soil, 397, 103-113.

Baker, G.H., Brown, G., Butt, K.R., Curry, J.P., Scullion, J., 2006. Introduced earthworms in agricultural and reclaimed land: their ecology and influences on soil properties, plant production and other soil biota. Biological Invasions, 8, 1301-1316. 
Bastardie, F., Capowiez, Y., Cluzeau, D., 2005. 3D characterization of earthworm burrow systems in natural soil cores collected from 12-year-old pasture. Applied Soil Ecology, 30, $34-46$.

Beylich, A., Graefe, U., 2012. Relationships between microannelid and earthworm activity. Landbauforschnung - vTI Agriculture and Forestry Research, Special Issue 357, 1-12.

Blouin, M., Hodson, M.E., Delgado, E.A., Baker, G., Brussaard, L., Butt, K.R., Dai, J., Dendoovern, L., Peres, G., Tondoh, J.E., Cluzeau, D., Brun, J.-J., 2013. A review of earthworm impact on soil function and ecosystem services. European Journal of Soil Science, 64, 161182.

Bouché, M.B., 1977. Stratégies lombriciennes. In: Lohm, U., Persson, T. (Eds.), Soil Organisms as Components of Ecosystems. Ecological Bulletins (Stockholm), 25, 122-132.

Briones, M.J.I., Schmidt, O., 2017. Conventional tillage decreases the abundance and biomass of earthworms and alters their community structure in a global meta-analysis. Global Change Biology 2017:1-24 DOI: 10.1111/gcb.13744

Brown, G.G., 1995. How do earthworms affect microfloral and faunal community diversityPlant and Soil, 170, 209-231.

Bruno, J.F., Stachowicz, J.J., Bertness, M.B., 2003. Inclusion of facilitation into ecological theory. Trends in Ecology and Evolution, 18, 119-125.

Butt, K.R., Frederickson, J., Morris, J.M., 1997. The Earthworm Inoculation Unit technique: an integrated system for cultivation and soil-inoculation of earthworm. Soil Biology and Biochemistry, 29, 251-257. 
Butt, K.R., Lowe, C.N., 2007. Presence of earthworm species within and beneath Lumbricus terrestris L. middens. European Journal of Soil Biology, 43, S57-S60.

Cameron, E.K., Bayne, E.M., 2011. An experimental test of facilitation between non-native earthworms. Canadian Journal of Zoology, 89, 1223-1230.

Capowiez, Y., Bottinelli, N., Jouquet, P., 2014. Quantitative estimates of burrow construction and destruction, by anecic and endogeic earthworm in repacked soil cores. Applied Soil Ecology, 74, 46-50.

Crooks, J.A., 2002. Characterizing the ecosystem-level consequences of biological invasions: the role of ecosystem engineers. Oikos, 97, 153-166.

Didden, W.A.M., 1990. Involvement of Enchytraeidae (Oligochaeta) in soil structure evolution in agricultural fields. Biology and Fertility of Soils, 9, 152-158.

Didden, W.A.M., 1993. Ecology of terrestrial Enchytraeidae. Pedobiologia, 37, 2-29.

Donadi, S., van der Heide, T., Piersma, T., van der Zee, E.M., Weerman, E.J., van de Koppel, J., Olff, H., Devine, C., Hernawan, U.E., Boers, M., Planthof, L., Eriksson, B.K., 2015. Multiscale habitat modification by coexisting ecosystem engineers drives spatial separation of microbenthic functional groups. Oikos, 124, 1502-1510.

Edwards, C.A., Bohlen, P.J., 1996. Biology and Ecology of Earthworms, third edition, Chapman \& Hall, London.

Eijsackers, H., 2011. Earthworms as colonizers of natural and cultivated soil environments. Applied Soil Ecology, 50, 1-13.

Eisenhauer, N., 2010. The action of an animal ecosystem engineer: identification of the main mechanisms of earthworm impacts on soil microarthropods. Pedobiologia, 53, 343-352. 
Eisenhauer, N., Fisichelli, N.A., Frelich, L.E., Reich, P.B., 2012. Interactive effects of global warming and 'global worming' on the initial establishment of native and exotic herbaceous plant species. Oikos, 121, 1121-1133.

Ettema, C.H. Wardle, D.A., 2002. Spatial soil ecology. Trends in Ecology and Evolution, 17, 177-183.

FAO, 1988. FAO/Unesco Soil Map of the World, World Resources Report 60, FAO, Rome, Reprinted as Technical Paper 20, ISRIC, Wageningen.

Frouz, J., Thébault, E., Pižl, V., Adl, S., Cajthaml, T., Baldrián, P., Háněl, L., Starý, J., Tajovský, K., Materna, J., Nováková, A., de Ruiter, P.C., 2013. Soil food web changes during spontaneous succession at post mining sites: a possible ecosystem engineering effect on food web organization? PLOS one, 8 (11), e79694.

Fugère, M., Bradley, R.L., Vellend, M., 2017. Exotic earthworms dispersion through protected forest areas and their potential impacts on nitrous oxide production. Biological Invasions, http://link.springer.com/article/10.1007/s10530-016-1331-y Accessed 21 December 2016.

Gbur, E.E., Stroup, W.W., McCarter K.S., Durham, S., Young, L.J., Christman, M., West, M., Kramer, M., 2012. Analysis of Generalized Linear Mixed Models in the Agricultural and Natural Resources Sciences, American Society of Agronomy, Madison.

Görres, JH, Savin, M.C., Amador, J.A., 1997. Dynamics of carbon and nitrogen mineralization, microbial biomass, and nematode abundance within and outside the burrow walls of anecic earthworm (Lumbricus terrestris). Soil Science, 162, 666-671.

Grigoropoulou, N., Butt, K.R., 2009. Interactions of juvenile Lumbricus terrestris with adults and their burrow systems in a two dimensional microcosm. Pesq. Agropec. Bras. 44, 964968. 
Grigoropoulou, N., Butt, K.R., 2010. Field investigations of Lumbricus terrestris spatial distribution and dispersal through monitoring of manipulated, enclosed plots. Soil Biology and Biochemistry, 42, 40-47.

Gunn, A., 1992. The use of mustard to estimate earthworm populations. Pedobiologia 36, 6567.

Hapca S., Houston A., Otten W., Baveye P., 2013. New local thresholding method for soil images by minimizing grayscale intra-class variance. Vadose Zone Journal, 12, doi:10.2136/vzj2012.0172

Hastings, A., Byers, J.E., Crooks, J.A., Cuddington, K., Jones, C.G., Lambrinos, J.G., Talley. T.S., Wilson, W.G., 2007. Ecosystem engineering in space and time. Ecology Letters, 10, 153164.

Hazelhoff, L., van Hoof, P., Imeson, A.C., Kwaad, F.J.P.M., 1981. The exposure of forest soil to erosion by earthworms. Earth Surface Processes and Landforms, 6, 235-250.

Hendrix, P.F. (Ed.), 2006. Biological Invasions Belowground. Earthworms as Invasive Species, Springer, Dordrecht.

Hilpert M., Glantz R., Miller C.T., 2003. Calibration of a pore-network model by a poremorphological analysis. Transport in Porous Media, 51, 267-285.

Horgan, G.W., 1998. Mathematical morphology for analysing soil structure from images. European Journal of Soil Science, 49, 161-173.

Iassonov P., Tuller M., 2010. Application of segmentation for correction of intensity bias in Xray computed tomography images. Vadose Zone Journal, 9, 187-191. 
IUSS Working Group WRB, 2015. World Reference Base for Soil Resources 2014, update 2015 International soil classification system for naming soils and creating legends for soil maps. World Soil Resources Reports, No. 106, FAO, Rome.

Jaakkola, A., 1984. Leaching losses of nitrogen from a clays soil under grass and cereal crops in Finland. Plant and Soil 76, 59-66.

Jones, C.G., Lawton, J.H., Shachak, M., 1994. Organisms as ecosystem engineers. Oikos, 69, 373-386.

Jones, C.G., Lawton, J.H., Shachak, M., 1997. Positive and negative effects of organisms as physical ecosystem engineers. Ecology, 78, 1946-1957.

Jouquet, P., Dauber, J., Lagerlöf, J., Lavelle, P., Lepage, J., 2006. Soil invertebrates as ecosystem engineers: intended and accidental effects on soil feedback loops. Applied Soil Ecology, 32, 153-164.

Karaban, K., Uvarov, A.V., 2014. Non-trophic effects of earthworms on enchytraeids: an experimental investigation. Soil Biology and Biochemistry, 73, 84-92.

Lavelle, P., Bignell, D., Lepage, M., Wolters, W., Roger, P., Ineson, P., Heal O.W., Dhillion, S., 1997. Soil function in a changing world: the role of invertebrate ecosystem engineers. European Journal of Soil Biology, 33, 159-193.

Lavelle, P., Spain A., Blouin, M., Brown, G., Decaëns, T., Grimaldi, M., Jiménez, J.J., McKey, D., Mathieu, J., Velasquez, E., Zangerlé, A., 2016. Ecosystem engineers in a self-organized soil: a review of concepts and future research questions. Soil Science, 181, 91-109.

Lee, K.E., 1985. Earthworms. Their Ecology and Relationships with Land Use. Academic Press, Sydney. 
Ligthart, T.N., Peek, G.J.W.C., Taber, E.J., 1993. A method for the three-dimesnional mapping of earthworm burrow systems. Geoderma, 57, 129-141.

Maraun, M., Alphei, J., Bonkowski, M., Buryn, R., Migge, S., Peter, M., Schaefer, M., Scheu, S., 1999. Middens of earthworm Lumbricus terrestri (Lumbricidae): microhabitats for microand mesofauna in forest soil. Pedobiologia, 43, 276-2787.

Migge-Kleian, S., McLean, M.A., Maerz, J.C, Heneghan, L., 2006. The influence of invasive earthworms on indigenous fauna in ecosystems previously uninhabited by earthworms. Biological Invasions, 8, 1275-1285.

Morel, J.G., Bokossa, M.C., Neerchal, N.K., 2003. Small sample correction for the variance of GEE estimators. Biometrical Journal, 45, 395-409.

Neher, D.A., 2010. Ecology of plant and free living nematodes in natural and agricultural soil. Annual Review of Phytopathology, 48, 371-394.

Nieminen, M., Hurme, T., Mikola, J., Regina, K., Nuutinen, V., 2015. Impact of earthworm Lumbricus terrestris living sites on the greenhouse gas balance of no-till arable soil. Biogeosciences, 12, 5481-5493.

Nordström, S., 1976. Growth and sexual development of earthworms in southern Sweden. Oikos, 27, 476-482.

Nuutinen, V., 2011. The meek shall inherit the burrow: feedback in earthworm soil modification. In: Karaca, A. (Ed.), Biology of Earthworms, Soil Biology 24, Springer, Berlin / Heidelberg, pp. 123-140 
Nuutinen V., Butt, K.R., Jauhiainen, L., 2011. Field margins and management affect settlement and spread of an introduced dew-worm (Lumbricus terrestris L.) population. Pedobiologia, 54S, S167-S172.

Nuutinen, V., Nieminen, M., Butt, K.R., 2006. Introducing deep burrowing earthworms (Lumbricus terrestris L.) into arable heavy clay under boreal conditions. European Journal of Soil Biology, 42, S269-S274.

O’Connor, F. B., 1962. The extraction of Enchytraeidae from soil. In: Murphy, P.W. (Ed.). Progress in Soil Zoology. Butterworth, London, pp. 279-285.

Odling-Smee, J., Erwin, D.H., Palkovacs, E.P., Feldman, M.W., Laland, K.M., 2013. Niche construction theory: a practical guide for ecologists. Quarterly Review of Biology, 88, 3-28.

Otsu, N., 1979. A threshold selection method from gray-level histograms. IEEE Transactions on Systems, Man, and Cybernetics, 9, 62-66.

Pérès, G., Bellido, A., Curmi, P., Marmonier, P., Cluzeau, D., 2010. Relationships between earthworm communities and burrow numbers under different land use systems. Pedobiologia, $54,37-44$.

Perreault, J.M., Whalen, J.K., 2006. Earthworm burrowing in laboratory microcosms as influenced by soil temperature and moisture. Pedobiologia, 50, 397-403.

Pirinen, P., Simola, H., Aalto, J., Kaukoranta, J.-P., Karlsson, P., Ruuhela, R., 2012. Climatological statistics of Finland 1981-2010. Report 2012, 1, Finnish Meteorological Institute, Helsinki. 
Pitkänen, J., Nuutinen, V., 1997. Distribution and abundance of burrows formed by

Lumbricus terrestris L. and Aporrectodea calginosa Sav. in the soil profile. Soil Biology and Biochemistry, 29, 463-467.

Porre, R.J., van Groenigen, J.W., De Deyn, G.B., de Goede, R.G.M., Lubbers, I.M., 2016. Exploring the relationship between soil mesofauna, soil structure and $\mathrm{N}_{2} \mathrm{O}$ emissions. Soil Biology and Biochemistry, 96, 55-64.

Procter, D.L.C., 1986. Fecundity, reproductive effort, age-specific reproductive tactics and intrinsic rate of natural increase of a high arctic nematode belonging to the genus Chiloplacus. Holarctic Ecology, 9, 104-108.

Räty, M., Huhta, V., 2003. Earthworms and pH affect communities of nematodes and enchytraeids in forest soil. Biology and Fertility of Soils, 38, 52-58.

Rodriguez, P., Arrate, J.A., Martinez-Madris, M., 2002. Life history of the oligochaete Enchutraeus coronatus (Annelida, Enchytraeidae) in agar culture. Invertebrate Biology. 121, 350-356.

SAS Institute Inc., 2015. SAS/STAT ${ }^{\circledR}$ 14.1 User's Guide, SAS Institute Inc., Cary, NC.

Scheu, S., 2003. Effect of earthworms on plant growth: patterns and perspectives. Pedobiologia, 47, 846-856.

Schlaghamerský. J., Eisenhauer, N., Frelich, L.E., 2014. Earthworm invasion alters enchytraeid community composition and individual biomass in northern hardwood forest of North America. Applied Soil Ecology, 83, 159-169. 
Schrader, S., Rogasik, H., Onasch, I., Jegou, D., 2007. Assessment of soil structural differentiation around earthworm burrows by means of X-ray computed tomography and scanning electron microscopy. Geoderma, 137, 378-387.

Schrader, S., Seibel, C., 2001. Impact of cultivation management in an agroecosystem on hot spot effects of earthworm middens. European Journal of Soil Biology, 37, 309-313.

Shipitalo, M.J., Le Bayon, R.-L., 2004. Quantifying the effects of earthworms on soil aggregation and porosity. In: Edwards, C.A. (Ed.), Earthworm Ecology, second edition, CRC Press, Boca Raton, pp. 183-200.

Sims, R.W., Gerard, B.M. 1999. Earthworms. Synopses of British Fauna (New Series), No. 31 (revised), Dorsett Press, Dorchester.

Singh, P., Heikkinen, J., Ketoja, E., Nuutinen, V., Palojärvi, A., Sheehy, J., Esala, M., Mitra, S., Alakukku, L. \& Regina, K., 2015. Tillage and crop residue management methods had minor effects on the stock and stabilization of topsoil carbon in a 30-year field experiment. Science of the Total Environment, 518-519, 337-344.

Sohlenius, B., 1979. A carbon budget for nematodes, rotifers and tardigrades in a Swedish coniferous forest soil. Holarctic Ecology, 2, 30-40.

Straube, D., Johnson, E.A., Parkinson, D., Scheu, S., Eisenhauer, N., 2009. Nonlinearity of effects of invasive ecosystem engineers on abiotic soil properties and soil biota. Oikos, 118, 885-896.

Stroud, J.L., Irons. D., Carter, J.E., Watts, C.W., Murray, P.J., Norris, S.L., Whitmore, A.P., 2016. Lumbricus terrestris middens are biological hotspots in a minimum tillage arable ecosystem. Applied Soil Ecology, 105, 31-35. 
Subler, S. Kirsch, A.S., 1998. Spring dynamics of soil carbon, nitrogen and microbial activity in earthworm middens in a notill cornfield. Biology and Fertility of Soils, 26, 243-249.

Tiunov, A.V., Bonkowaki, M., Alphei, J., Scheu, S., 2001. Miocroflora, Protozoa and Nematoda in Lumbricus terrestris burrow walls: a laboratory experiment. Pedobiologia, 45, 46-60,

Turpeinen, T., Myllys M., Kekäläinen P., Timonen J., 2015. Interface detection using a quenched-noise version of the Edwards-Wilkinson equation. IEEE Transactions on Image Processing, 24, 5696-5705.

Turtola, E., Alakukku, L., Uusitalo, R., Kaseva, A., 2007. Surface runoff, subsurface drainflow and soil erosion as affected by tillage in a clayey Finnish soil. Agricultural and Food Science, 16, 332-351.

Turtola. E., Jaakkola, A., 1987. Viljelykasvin vaikutus ravinteiden huuhtoutumiseen savimaasta Jokioisten huuhtoutumiskentällä v. 1983-1986 (in Finnish). Maatalouden tutkimuskeskus, Tiedote 22/87.

Uvarov, A.V., 2009. Inter- and intraspecific interactions in lumbricid earthworms: their role for earthworm performance and ecosystem functioning. Pedobiologia, 53, 1-27.

van Cappelle, C., Schrader, S., Brunotte, J., 2012. Tillage induced changes in the functional diversity of soil biota: a review with a focus on German data. European Journal of Soil Biology, 50, 165-181.

van Groenigen, J.W., Lubbers, I.M., Vos, H.M.J., Brown, G.G., De Deyn, G.B., van Groenigen, K.J., 2014. Earthworm increase plant production: a meta-analysis. Scientific Reports, 4, 6365. 
van Vliet, P.C.J., West, F.T., Hendrix, P.F., Coleman, D.C., 1993. The influence of Enchytraeidae (Oligochaeta) on the soil porosity of small microcosms. Geoderma, 1993,287299.

Wardle, D.A., 2006. The influence of biotic interactions on soil biodiversity. Ecology Letters, 9, 870-886.

Whalen, J.K., Han, L., Dutilleul, P., 2015. Burrow refilling behaviour of Aporrectodea turgida (Eisen) and Lumbricus terrestris L. as revealed by X-ray computed tomography scanning: graphical and quantitative analyses. Canadian Journal of Soil Science, 95, 231-235.

Yeates, G.W. 2007. Diversity of nematodes. In: Benckiser, G., Schnell, S. (Eds.), Biodiversity in Agricultural Production Systems, CRC Press, Boca Raton, pp. 215-235. 


\section{Tables}

Table 1. The response variables, their distributional assumptions and link functions in the generalized linear mixed models used in statistical analyses of the data.

\begin{tabular}{|c|c|c|c|}
\hline Statistical analysis & Response variable & Distribution & $\begin{array}{l}\text { Link } \\
\text { function }\end{array}$ \\
\hline $\begin{array}{l}\text { Dispersal gradient of } \\
\text { L. terrestris }\end{array}$ & Number of middens $\left(\mathrm{m}^{-2}\right)$ & Poisson & $\log$ \\
\hline \multirow{5}{*}{$\begin{array}{l}\text { Faunal effects } \\
\text { (Midden scale) }\end{array}$} & $\begin{array}{l}\text { Proportion of anecic and epigeic species of all } \\
\text { earthworm individuals }\end{array}$ & Binomial & $\operatorname{logit}$ \\
\hline & Number of earthworms (ind. $0.165 \mathrm{~m}^{-2}$ ) & Poisson & $\log$ \\
\hline & Earthworm total mass ( $\mathrm{g}$ fresh mass $0.165 \mathrm{~m}^{-2}$ ) & Gamma & $\log$ \\
\hline & Number of nematodes (ind. $\mathrm{cm}^{-2}$ ) & Neg. binomial & $\log$ \\
\hline & Number of enchytraeids (ind. $22 \mathrm{~cm}^{-2}$ ) & Poisson & $\log$ \\
\hline \multirow{3}{*}{$\begin{array}{l}\text { Faunal effects } \\
\text { (Strip scale) }\end{array}$} & $\begin{array}{l}\text { Abundance of epigeic and endogeic } \\
\text { earthworms (ind. } 0.165 \mathrm{~m}^{-2} \text { ) }\end{array}$ & Poisson & $\log$ \\
\hline & Abundance of nematodes (ind. $\mathrm{cm}^{-2}$ ) & Neg. binomial & $\log$ \\
\hline & Abundance of enchytraeids (ind. $22 \mathrm{~cm}^{-2}$ ) & Poisson & $\log$ \\
\hline \multirow[b]{2}{*}{ Soil porosity } & Porosity (proportion of sample volume) & Beta & $\operatorname{logit}$ \\
\hline & $\begin{array}{l}\text { Porosity after } L \text {. terrestris main burrow } \\
\text { excluded }\end{array}$ & Beta & $\operatorname{logit}$ \\
\hline
\end{tabular}


Table 2. Test results of the fixed main and interaction effects in the generalized linear mixed models for the proportion of anecic and epigeic individuals of all earthworm individuals, earthworm number and fresh mass (statistically significant P-values are in bold; $n=$ the number of observations).

\begin{tabular}{lcccccccccc}
\hline & \multicolumn{3}{c}{$\begin{array}{c}\text { Anecic and epigeic } \\
\text { proportion }(\mathrm{n}=70)^{1)}\end{array}$} & \multicolumn{3}{c}{$\begin{array}{c}\text { Earthworm density } \\
(\mathrm{n}=80)\end{array}$} & \multicolumn{3}{c}{ Earthworm fresh mass } \\
Effect & $\mathrm{df}$ & $\mathrm{F}$ & $\mathrm{P}$ & $\mathrm{df}$ & $\mathrm{F}$ & $\mathrm{P}$ & $\mathrm{df}$ & $\mathrm{F}$ & $\mathrm{P}$ \\
\cline { 2 - 11 } & 1,34 & 0.19 & 0.67 & 1,36 & 2.64 & 0.11 & 1,36 & 7.88 & $\mathbf{0 . 0 1}$ \\
Strip & 1,34 & 0.33 & 0.57 & 1,36 & 0.70 & 0.41 & 1,36 & 0.03 & 0.88 \\
Zone & 1,34 & 0.01 & 0.91 & 1,36 & 0.14 & 0.71 & 1,36 & 0.00 & 0.96 \\
Strip $\times$ Zone & 1,28 & 0.17 & 0.68 & 1,36 & 15.25 & $<\mathbf{0 . 0 0 1}$ & 1,36 & 6.18 & $\mathbf{0 . 0 2}$ \\
Midden & 1,28 & 0.79 & 0.38 & 1,36 & 0.75 & 0.39 & 1,36 & 0.00 & 0.99 \\
Strip $\times$ Midden & 1,28 & 0.13 & 0.72 & 1,36 & 7.87 & $\mathbf{0 . 0 1}$ & 1,36 & 0.43 & 0.52 \\
Zone $\times$ Midden & 1,28 & 0.46 & 0.50 & 1,36 & 1.02 & 0.32 & 1,36 & 0.52 & 0.48 \\
Strip $\times$ Zone $\times$ Midden & & & & & & & & & & \\
\hline
\end{tabular}

1) The proportion is missing for samples with no earthworm individuals. 
Table 3. Test results for the comparison of three zones in two strips in terms of the fieldscale overall abundance of epigeic and endogeic earthworms and nematodes in the field soil (calculated for Zones 1 and 2 using weighted averages that accounted for the different proportions of midden and non-midden soil; $\mathrm{n}=$ the number of observations).

\begin{tabular}{|c|c|c|c|c|c|c|c|}
\hline \multirow[b]{3}{*}{ Effect } & \multirow{2}{*}{\multicolumn{3}{|c|}{$\begin{array}{l}\text { Earthworms } \\
\quad(\mathrm{n}=60)\end{array}$}} & \multicolumn{4}{|c|}{ Nematodes } \\
\hline & & & & & $n=30)$ & & $(\mathrm{n}=29)^{1)}$ \\
\hline & $\mathrm{df}$ & $\mathrm{F}$ & $\mathrm{P}$ & $\mathrm{df}$ & $\mathrm{F}$ & $\mathrm{P}$ & $\mathrm{P}$ \\
\hline Strip & 1,54 & 0.05 & 0.83 & 1,24 & 0.00 & 1.00 & 0.32 \\
\hline Zone & 2,54 & 2.45 & 0.10 & 2,24 & 1.72 & 0.20 & 0.48 \\
\hline Strip $\times$ Zone & 2,54 & 1.76 & 0.18 & 2,24 & 0.28 & 0.76 & 0.91 \\
\hline
\end{tabular}

1) Analysed using data without one deviant midden - non-midden pair in Zone 2 of Strip 1. 
Table 4. Test results of the fixed main and interaction effects in the generalized linear mixed models for nematode and enchytraeid abundance (statistically significant P-values are in bold, $\mathrm{n}=$ number of observations).

\begin{tabular}{lccccccc}
\hline & \multicolumn{3}{c}{ Nematodes } & \multicolumn{3}{c}{ Enchytraeids } \\
& \multicolumn{3}{c}{$(\mathrm{n}=40)$} & & $(\mathrm{n}=38)^{1}$ & \multicolumn{3}{c}{$(\mathrm{n}=40)$} \\
Effect & $\mathrm{df}$ & $\mathrm{F}$ & $\mathrm{P}$ & $\mathrm{P}$ & $\mathrm{df}$ & $\mathrm{F}$ & $\mathrm{P}$ \\
\hline Strip & 1,16 & 0.33 & 0.57 & 0.23 & 1,16 & 3.28 & 0.09 \\
Zone & 1,16 & 2.94 & 0.11 & 0.12 & 1,16 & 0.84 & 0.37 \\
Strip $\times$ Zone & 1,16 & 0.11 & 0.75 & 0.81 & 1,16 & 0.09 & 0.77 \\
Midden & 1,16 & 1.90 & 0.19 & $\mathbf{0 . 0 1}$ & 1,16 & 5.41 & $\mathbf{0 . 0 3}$ \\
Strip $\times$ Midden & 1,16 & 1.39 & 0.26 & 0.39 & 1,16 & 0.46 & 0.51 \\
Zone $\times$ Midden & 1,16 & 0.86 & 0.37 & 0.71 & 1,16 & 0.08 & 0.79 \\
Strip $\times$ Zone $\times$ Midden & 1,16 & 0.13 & 0.73 & 0.64 & 1,16 & 0.31 & 0.58 \\
\hline
\end{tabular}

${ }^{1)}$ Analysed using data without one deviant midden - non-midden pair in Zone 2 of Strip 1. 


\section{Figure legends}

Figure 1. Field work design at the Kotkanoja site. The squares (not to scale) show sites of midden counting in the direct-drilled Strips 1 and 2. Zones 1-3 (shaded areas) denote the areas where fauna and soil were sampled. "Tile" refers to subdrain and the associated values are distances (m) from the original L. terrestris inoculation area. " $L$ " and "R" refer to left and right plot margin positions, "C" to plot centre-line position.

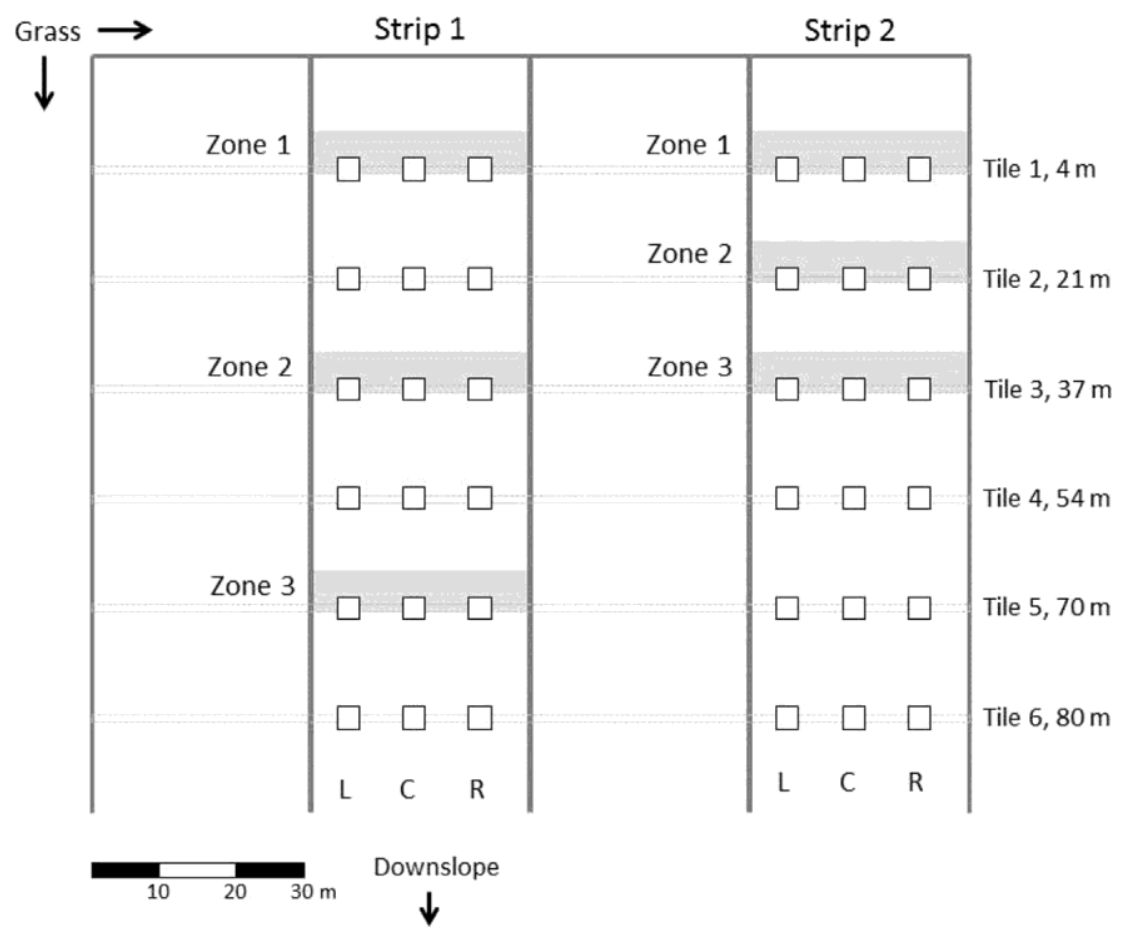


Fig. 2. Soil moisture content (arithmetic mean $\pm \mathrm{SD}, \mathrm{n}=50$ ) over Zones 1-3 in Strips 1 and 2.
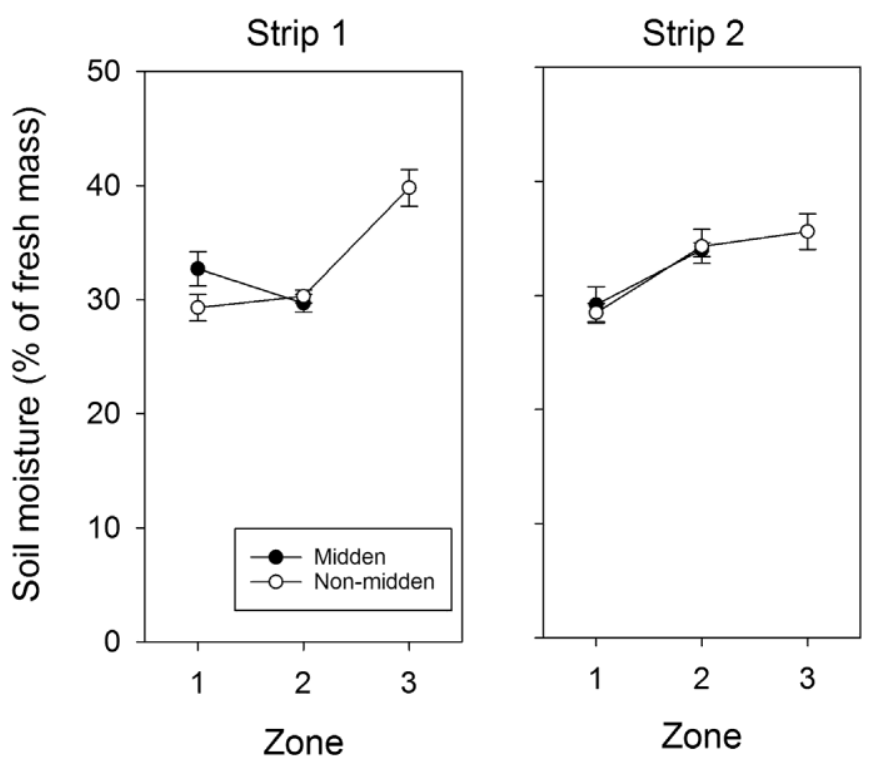

Fig. 3. Dispersal gradient of L. terrestris in the two strips described by polynomials fitted to the midden density data at the strip centers (red lines with circles) and two margins (black solid and dotted lines with crosses).
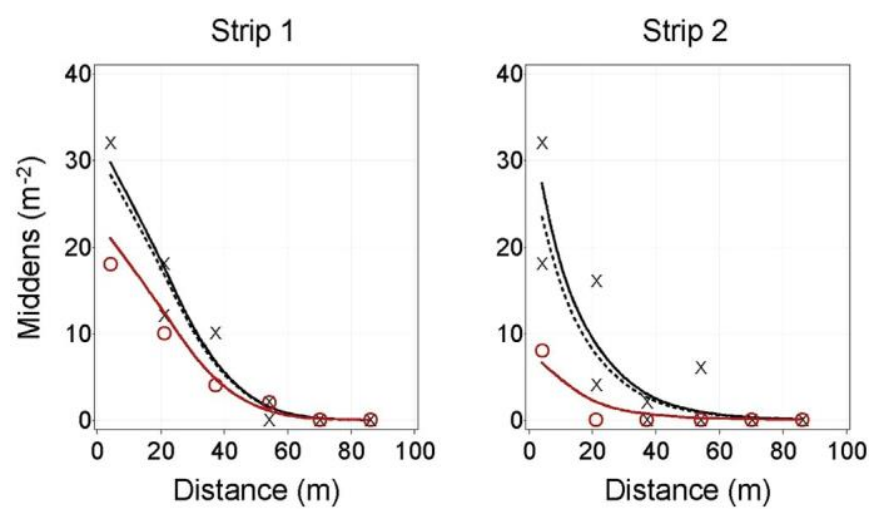
Figure 4. Mean total earthworm abundance in $0.0165 \mathrm{~m}^{2}$ samples \pm SEM in L. terrestris middens and adjacent non-midden areas (ten pairs for each of the four strip $\times$ zone combination; $\mathrm{n}=80$ ) close to the L. terrestris inoculation site (Zone 1) and in the leading edge of the dispersal gradient (Zone 2).

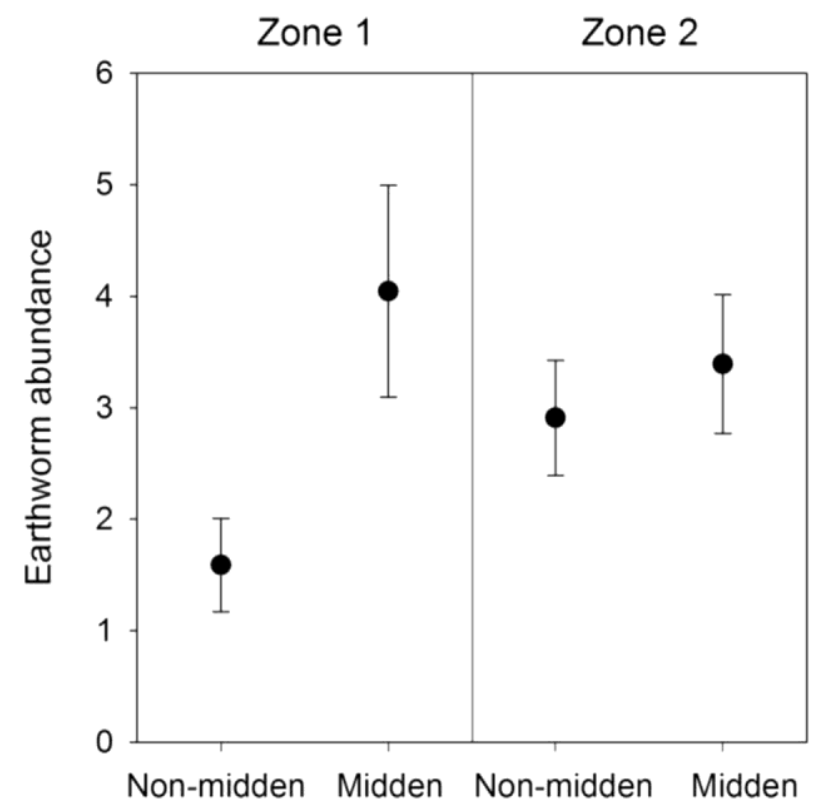

Fig. 5. Mean abundance \pm SEM of nematodes (ind. $\mathrm{cm}^{-2}$ ) and enchytraeids (ind. $22 \mathrm{~cm}^{-2}$ ) in L. terrestris middens and adjacent non-midden areas (five pairs for each of the four strip $\times$ zone combination; $\mathrm{n}=40$ ).
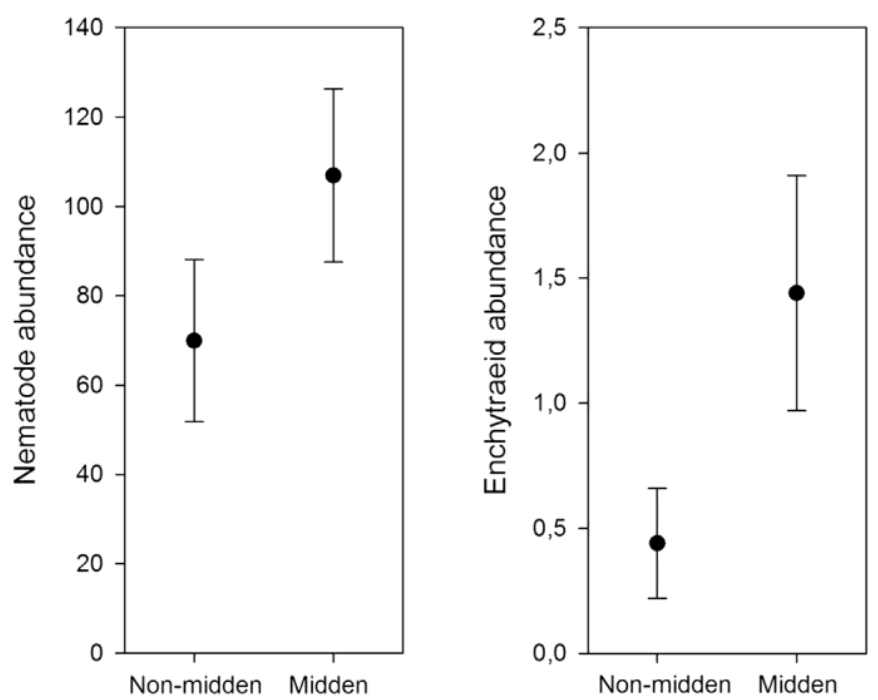
Fig. 6. Mean abundance \pm SEM of endogeic and epigeic earthworms (ind. $0.0165 \mathrm{~m}^{-2}, \mathrm{n}=60$ ) and nematodes (ind. $\mathrm{cm}^{-2}, \mathrm{n}=30$ ) in Zones 1-3 (midden and non-midden areas in Zones 1 and 2 are combined in their relative proportions; without one deviant nematode observation, the mean abundance of nematodes in Zone 2 decreased to 81 ind. $\mathrm{cm}^{-2}(\mathrm{SEM}=16)$.
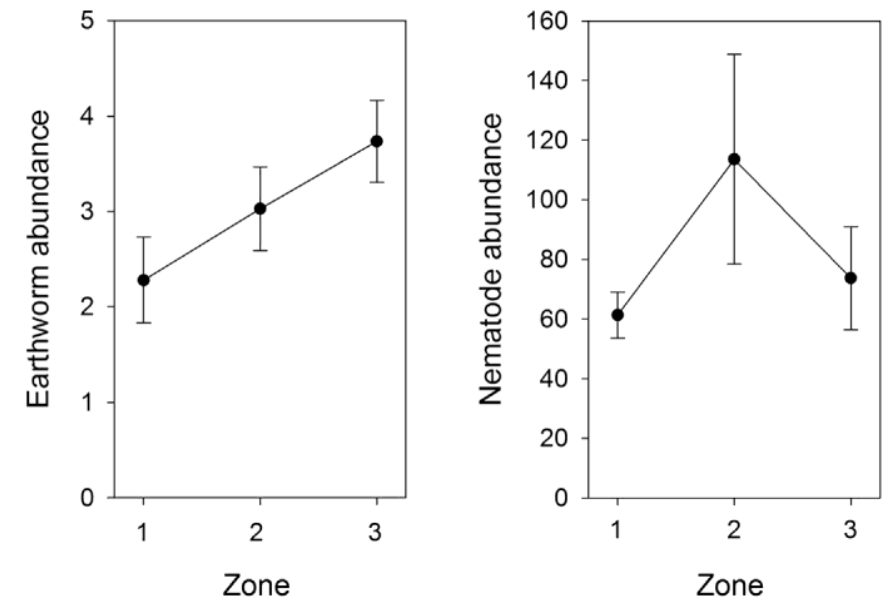
Fig 7. Top: Soil porosity as a proportion of sample volume (the average of the means of the two zones \pm SEM; $n=20$ ) of the imaged soil samples with the main L. terrestris burrow included or excluded. Bottom: Visualization of different sized soil porosity for a midden sample taken from Zone 1 (connection of pores to soil surface is evident; pore radii (r) are indicated by colour coding with the largest continuous pore being the L. terrestris main burrow).
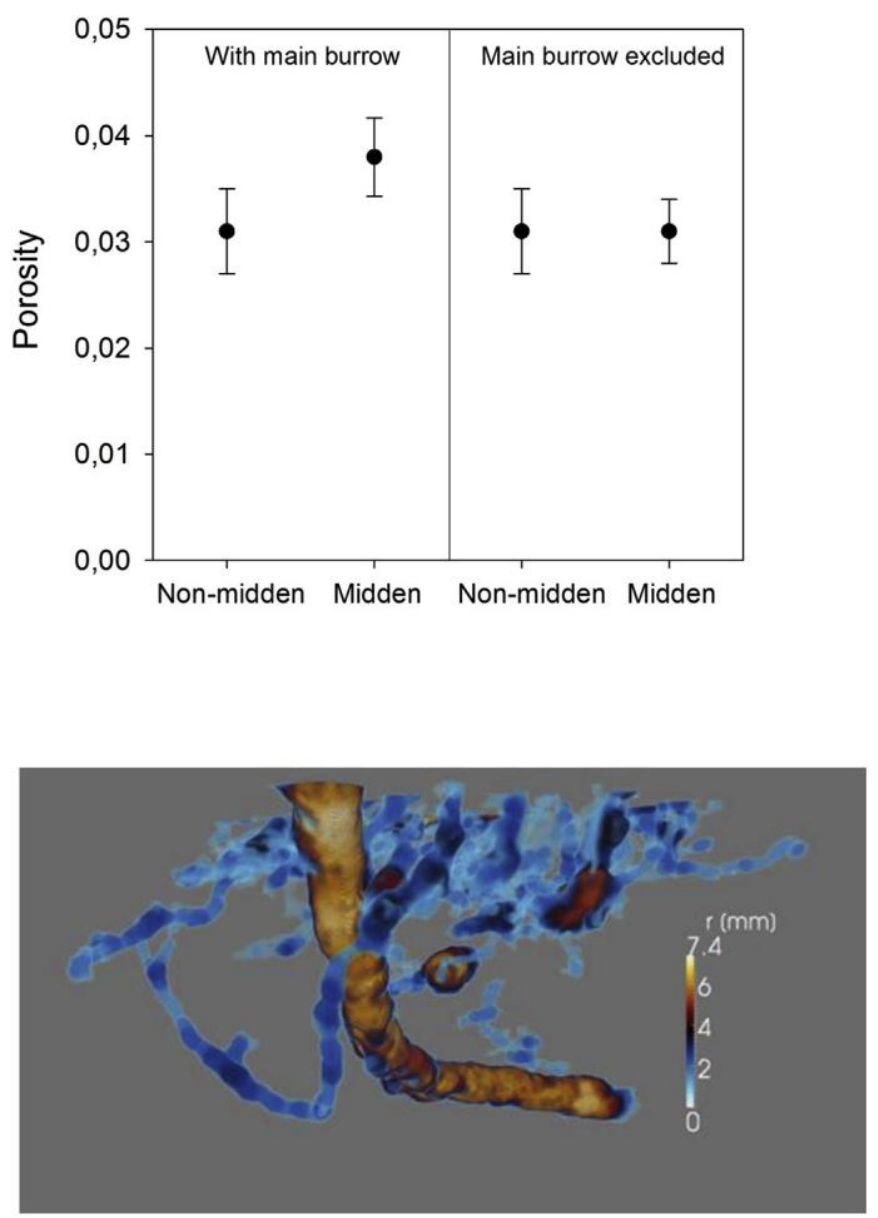
Fig 8. Pore diameter distributions (all imagined samples combined, $\mathrm{n}=20$ ) for control samples (uppermost row), midden samples (middle row), and midden samples with the main L. terrestris burrow excluded (bottom row) in Zone 1 and 2.

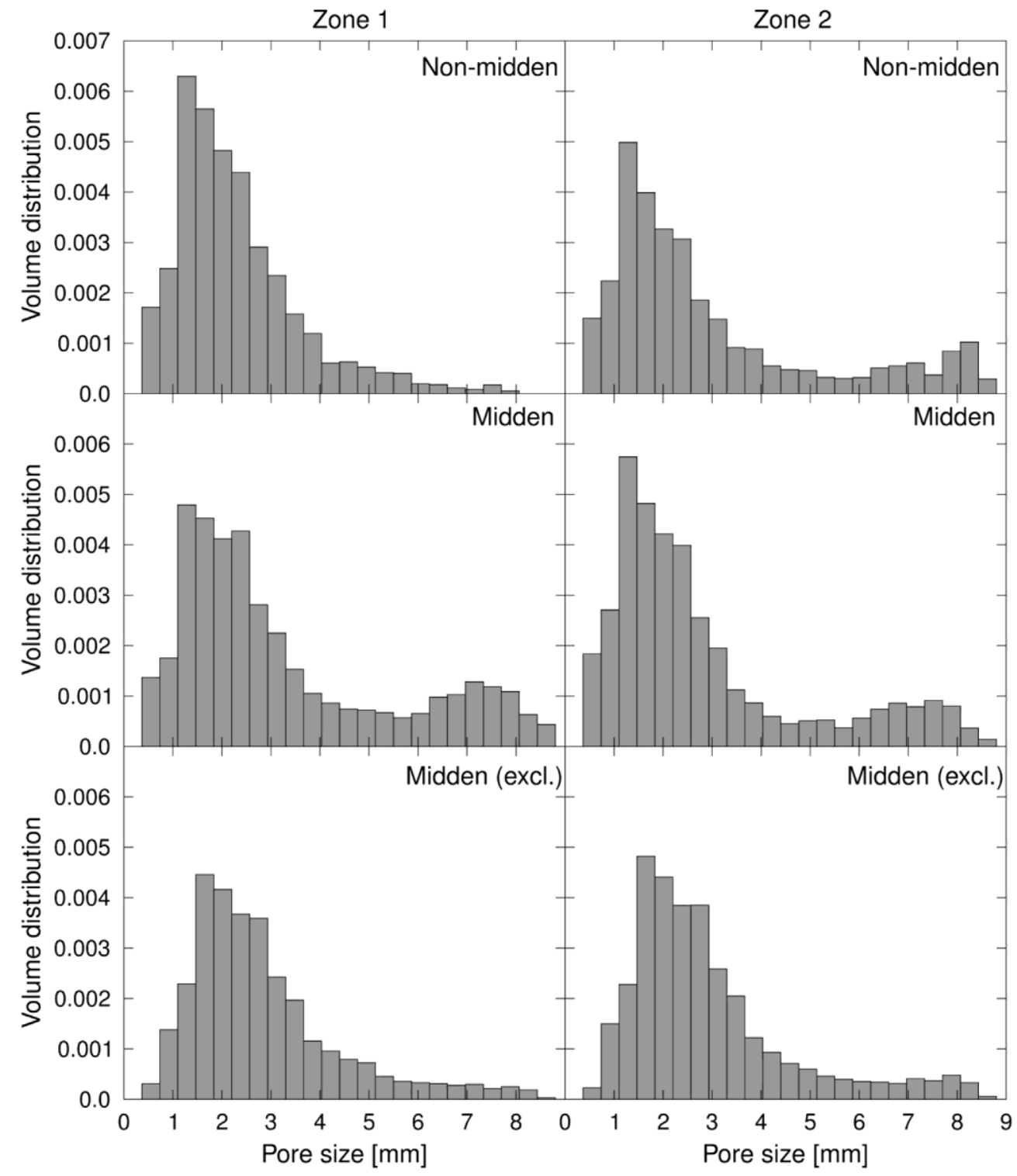

